\title{
WEIGHTED COMPOSITION OPERATORS FROM DIRICHLET-TYPE SPACES INTO STEVIĆ-TYPE SPACES
}

\author{
XIANGLing ZHU
}

Abstract. The boundedness and compactness of weighted composition operators from Dirichlettype spaces into Stević-type spaces are investigated in this paper. Some estimates for the essential norm of weighted composition operators are also given.

Mathematics subject classification (2010): 30H10, 47B33.

Keywords and phrases: Weighted composition operator, Dirichlet-type space, Stević-type space.

\section{REFERENCES}

[1] E. AbBasi, H. VAeZI AND S. LI, Essential norm of weighted composition operators from $H^{\infty}$ to $n$-th weighted type spaces, Mediterr. J. Math. (2019) 16:133, https://doi.org/10.1007/s00009-019-1409-8.

[2] E. ABBASI AND X. ZHU, Weighted composition operators from the Besov space into $n$-th weighted type spaces, submitted, 2019.

[3] F. Colonna, New criteria for boundedness and compactness of weighted composition operators mapping into the Bloch space, Cent. Eur. J. Math. 11 (2013), 55-73.

[4] F. COLONNA AND M. TJANI, Weighted composition operators from the Besov spaces into the weighted-type space $H_{\mu}^{\infty}$, J. Math. Anal. Appl. 402 (2013), 594-611.

[5] F. COLONNA AND M. TJANI, Operator norms and essential norms of weighted composition operators between Banach spaces of analytic functions, J. Math. Anal. Appl. 434 (2016), 93-124.

[6] L. Comtet, Advanced Combinatorics, D. Reidel, Dordrecht, 1974.

[7] C. Cowen And B. MacCluer, Composition Operators on Spaces of Analytic Functions, CRC Press, Boca Raton, FL, 1995.

[8] J. DU, S. Li AND Y. ZHANG, Essential norm of generalized composition operators on Zygmund type spaces and Bloch type spaces, Ann. Polon. Math. 119 (2017), 107-119.

[9] P. Galindo, M. Lindström And S. STEvić, Essential norm of operators into weighted-type spaces on the unit ball, Abstr. Appl. Anal. Vol. 2011, Article ID 939873, (2011), 13 pages.

[10] Q. HU AND S. LI, Essential norm of weighted composition operators from the Bloch space and the Zygmund space to the Bloch space, Filomat 32 (2018), 681-691.

[11] S. Li AND S. STEVIĆ, Products of composition and differentiation operators from Zygmund spaces to Bloch spaces and Bers spaces, Appl. Math. Comput. 217 (2010), 3144-3154.

[12] S. Li AND S. STEVIĆ, Generalized weighted composition operators from $\alpha$-Bloch spaces into weighted-type spaces, J. Inequal. Appl. Vol. 2015, Article No. 265, (2015), 12 pages.

[13] B. MACClueR AND R. ZHAO, Essential norms of weighted composition operators between Blochtype spaces, Rocky Mount. J. Math. 33 (4) (2003), 1437-1458.

[14] K. Madigan And A. Matheson, Compact composition operators on the Bloch space, Trans. Am. Math. Soc. 347 (7) (1995), 2679-2687.

[15] H. Schwartz, Composition operators on $H^{p}$, Thesis, University of Toledo (1969).

[16] B. SEHBA And S. STEvić, On some product-type operators from Hardy-Orlicz and Bergman-Orlicz spaces to weighted-type spaces, Appl. Math. Comput. 233 (2014), 565-581.

[17] S. STEvić, Composition operators from weighted Bergman space to $n$-th weighted space on the unit disk, Discrete Dyn. Nat. Soc. Vol. 2009, Article ID 742019, (2009), 11 pages. 
[18] S. STEVIĆ, Norm and essential norm of composition followed by differentiation from $\alpha$-Bloch spaces to $H_{\mu}^{\infty}$, Appl. Math. Comput. 207 (2009), 225-229.

[19] S. STEVIĆ, On a new integral-type operator from the Bloch space to Bloch-type spaces on the unit ball, J. Math. Anal. Appl. 354 (2009), 426-434.

[20] S. STEvić, Composition followed by differentiation from $H^{\infty}$ and the Bloch space to $n$-th weightedtype spaces on the unit disk, Appl. Math. Comput. 216 (2010), 3450-3458.

[21] S. STEvić, Composition operators from the Hardy space to the $n$th weighted-type space on the unit disk and the half-plane, Appl. Math. Comput. 215 (2010), 3950-3955.

[22] S. STEVIĆ, Norm and essential norm of an integral-type operator from the Dirichlet space to the Bloch-type space on the unit ball, Abstr. Appl. Anal. Vol. 2010, Article ID 134969, (2010), 9 pages.

[23] S. STEvić, Weighted differentiation composition operators from $H^{\infty}$ and Bloch spaces to $n$-th weighted-type spaces on the unit disk, Appl. Math. Comput. 216 (2010), 3634-3641.

[24] S. STEVIĆ, Weighted differentiation composition operators from the mixed-norm space to the $n$-th weigthed-type space on the unit disk, Abstr. Appl. Anal. Vol. 2010, Article ID 246287, (2010), 15 pages.

[25] S. STEVIĆ, Weighted radial operator from the mixed-norm space to the nth weighted-type space on the unit ball, Appl. Math. Comput. 218 (2012) 9241-9247.

[26] S. STEVIĆ, Essential norm of some extensions of the generalized composition operators between kth weighted-type spaces, J. Inequal. Appl. Vol. 2017, Article No. 220, (2017), 13 pages.

[27] S. STEVIĆ, A. Sharma AND A. Bhat, Essential norm of products of multiplication composition and differentiation operators on weighted Bergman spaces, Appl. Math. Comput. 218 (2011), 2386-2397.

[28] S. STEVIĆ, Z. ZHOU AND R. Chen, Weighted composition operators between Bloch type spaces in the polydisc, Sb. Math. 201 (1-2) (2010), 289-319.

[29] S. UEKI AND L. LUO, Essential norms of weighted composition operators between weighted Bergman spaces of the ball, Acta Sci. Math. 74 (2008), 829-843.

[30] R. ZHAO, Essential norms of composition operators between Bloch type spaces, Proc. Am. Math. Soc. 138 (2010), 2537-2546.

[31] K. ZHU, Bloch type spaces of analytic functions, Rocky Mount. J. Math. 23 (1993), 1143-1177.

[32] K. Zhu, Operator Theory in Function Spaces, 2ed edition, Math. Surveys and Monographs, Vol. 138, American Mathematical Society: Providence, Rhode Island, 2007.

[33] X. ZHU, Essential norm of generalized weighted composition operators on Bloch-type spaces, Appl. Math. Comput. 274 (2016), 133-142.

[34] X. ZHU AND J. Du, Weighted composition operators from weighted Bergman spaces to Stević-type spaces, Math. Ineq. Appl. 22 (2019), 361-376. 